\title{
Book Classification and the Problem of: Change
}

\author{
Mr. Haykin is editor of the Decimal \\ Classification.
}

$\mathrm{T}$ HERE IS A PARADOX in the attitude of librarians toward the classification of their book collections. On the one hand, they point to the inadequacies of the system they employ and blithely-perhaps one should say, innocently-proceed to make changes in the system, ostensibly either in order to correct flaws in the system or to adapt it to the "local situation." On the other hand, they are aware of-indeed, they point to-the cost of change and appear satisfied if the system provides a place, any place, for a topic without reference to the unity and consistency of the system. Because this paradox exists, it is necessary to examine the various factors in the problem of change as they affect libraries. It is expected that this examination will provide the basis for more rational solutions of the problem.

Modern systems of classification for library materials are based primarily on subject relationships, largely disregarding such considerations as language, format, chronology (date of publicaion, age or period covered, obsolescence), or relegating them to a secondary order. The obvious assumption that underlies subject relationships is that users of the books on the shelves, both the library's public and the library's staff, are best served by a subject arrangement. Otherwise, libraries could find justification for arrangement by author. Law libraries, for example, sometimes arrange treatises by author, so that books on diverse subjects stand together on the shelves and books on the same topic are scattered. The underlying assumption here is that the user of the library would not be aware of, or concerned with, books dealing with subjects related to the one he is concerned with at the moment and that his needs would be satisfied by resorting to the alphabetical arrangement on the shelves by author or to the catalog under the appropriate subject heading. Many libraries, notably public libraries, make their primary arrangement by language, that is, all the German books together, the French books together, and so on. However, the books in each language are then arranged by subject following the order of the system of classification by subject. In order to make the most economical use of space libraries frequently group their books by size, shelving octavo volumes separately, then quartos, folios and extraordinarily large books, each as a separate group. Here, too, however, each group is virtually always arranged according to the subject classification. Largely, then, modern libraries deem it best to arrange their books by subject, the general assumption being that a library following the open-shelf policy or nearly all American public and school libraries, the user of the library may either find the book he desires among other books on the same subject or, failing to find it, would be satisfied with another book on the same subject. For the reference and reader-advisory staff of the library a subject arrangement is considered a definite advantage, since it often 
enables them to find several books on the same subject of which one may contain precisely the information sought. To a casual user of the shelves the subject arrangement also has a suggestive value; that is, it leads the user to an interest in related topics, which in a subject arrangement would be contiguous or near to the subject sought.

An important implication in any classification based on subject arrangement is that familiarity with a subject implies on the part of the user of the library some sense of the structure of the subject matter and of the relationships of topics within the subject. Thus, for example, it is assumed that the user who seeks a book on income tax would be aware that taxation is an element of public finance, and that it is associated with customs and tariff, the public debt, government bonds, and the like; so that, if he encountered books on any of these topics, he would expect to find the material he seeks near them. If there were no such assumption, library needs would be satisfied by a sequence of unrelated topics, the sequence being arranged purely arbitrarily in the order in which they initially come up for consideration, or alphabetically, or by any other method other than one based on subject relationships. To equip any such arrangement with a system of notation would be a relatively simple matter.

A user of the open shelves of a particular library would become familiar with the location of books on the topics of his interest and return to them without difficulty. Yet the suggestive value of a true subject arrangement would be lost and any shifting of the books made necessary by the growth of the collection or for administrative reasons would require the user to learn a new location for his topic.

Virtually all makers of subject classifications have recognized the value of the common use of a single system. Melvil Dewey recognized this from the very beginning.
Although the Library of Congress classification was devised solely with the needs of the Library of Congress in mind, its use by a considerable number of libraries has increased its value to other libraries, not only because the class numbers on Library of Congress catalog cards eliminates most of the cost of classifying, but interlibrary loans and other mutual library services are facilitated and improved. The universal use of the Dewey Decimal Classification in public, school, and university and college libraries has encouraged schools, colleges, and universities to offer elementary instruction in the system, presumably because it helps the students in the use of the books on the shelves and because of its continuing help in the use of other libraries. These considerations have a bearing as well on centralized classification and the problem of change as will be brought out later.

Subject classifications are the rule in modern libraries and are considered helpful to the reference and reader-advisory staff, the habitual users of the library, in subsequent use of other libraries, and in interlibrary relations and services. This is the raison d'etre of subject classification, aside from any sense of orderliness or conformity to a system of knowledge which they impart. Libraries can hardly avoid subject classification for their open-shelf or even limited-access collections. The problem of change must, therefore, in the first instance be considered in this context. Only insofar as circumstances diminish the value of subject classification can other factors, no matter how important, become the dominant considerations.

The discovery of new facts and the shedding of new light on old facts tend to affect the organization of knowledge, hence the structure of book classification. If subject classification has value, it derives it primarily from its continuing relationship to the organization of knowledge. Those who have 
devoted any time to describing and criticizing existing subject classification have invariably found fault with the failures of logic in their structure and the lag between the schedules and advancing knowledge. Anyone familiar with the Dewey Decimal Classification has heard criticism of the organization of the roo class (Philosophy), of the separation of the 800 class from the 400 class, of the lack of adequate provision for topics in modern physics, for the extensive literature of sociology, for modern psychology. The clear implication of this criticism is that the system is expected not only to expand but to correct what is no longer valid in the light of increased knowledge. In fact, the editors through the years have been urged by libraries not only to expand particular parts of the classification not deemed by the libraries sufficiently detaled for their needs, but also, and frequently, to correct what they deemed to be errors, whereas in many instances they were not out of line with the state of knowledge years ago, but in the light of present-day knowledge were no longer valid. Even the separation of 400 from 800 and of 300 from 900 can be explained on the basis of the Baconian system or an accepted order of the sciences at the time the Dewey Decimal Classification came into being; yet hardly anybody would find the separation reasonable now.

The history of the Dewey Decimal Classification, through its successive editions, is not by any means free of change. It is true that most of its development was by accretion, yet changes in varying degree, other than expansions, have been made from the very beginning, even if we leave the first, obviously tentative, edition out of consideration. As examples of changes from the 2 nd edition through the r 2 th one might cite the following: I) 333.9 meant fisheries (obviously in connection with its economic aspects) in the 2 nd through the 9th edition, and water rights thereafter ; 2 ) Mormonism, which was 298 through eight successive editions and since the Ioth has been 289 ; 3) general European history, the periods of which through the 9 th edition were assigned the numbers 940.1-940.9 and in the Ioth were contracted to 940.1-940.2 in order to provide shorter numbers for the War (940.3-.4) and 940.5-.9 for succeeding periods; 4) psychology, which has been classified dichotomously in 130 and 150 through the 12 th edition, was provided in the $13^{\text {th }}$ with an "alternativ expansion based on present-day lines of thot"; and 5) systematic botany, which through fifteen editions has, contrary to the general principle of structure in classification, proceeded from the most complex to the simplest, was in the $14^{\text {th }}$ edition provided with an alternative abridged from the Universal Decimal Classification and embracing, in the reverse order, all systematic botany under 582 rather than $582-589$ as in previous editions.

The change from 940.1-.9 to 940.1-.4, it might be noted, involved considerable numbers of books in all libraries since the numbers covered the general history of Europe from the fall of the Roman Empire to date. Those libraries which decided to keep the Dewey Decimal Classification were obliged to reclassify their books on this subject. In all libraries there were considerable numbers classified in $940 \% .1$ through 940.9 which, by the change in the roth edition, had to be reclassified. Otherwise, each library had to develop on its own the classification for the history of Europe beginning with the First World War. If it did not do so, it would to some extent lose the benefit derived from the use of a common classification and could not make direct use of the Decimal Classification numbers on Library of Congress cards. It is doubtless true that some libraries at the present time are still using editions antecedent to the roth. If, however, a sound and up-to-date classifica- 
tion is of value to libraries, these libraries are behind the procession and fail to reap the full benefit of a common classification and of the cooperative and centralized work of the Library of Congress, the H. W. Wilson Company, and the American Library Association.

There is no denying or minimizing the economic factor in classification. A substantial part of the cost of preparing library materials for use is chargeable to classification. It is this fact, among others, which pointed the way to cooperative and centralized classification. Melvil Dewey himself recognized the economic waste involved in separate classification of a book by a number of libraries, even aside from the fact that cooperative classification offers the means of securing greater subject competence for the task. And even more than the cost of original classification, libraries must look with a critical eye at the probable cost of reclassification. Many a library administrator, burdened with the necessity of keeping down the cost of preparing materials for use in order to maintain basic library services, is willing to assume that a book once classified should remain classified regardless of the importance of subject classification and of the validity of the class numbers. These administrators frequently decide to accept without questioning, and certainly without study or investigation, class numbers provided by centralized, cooperative classification services. If subject classification and the validity of numbers are really important, this attitude on the part of administrators is to be deplored, yet the motives behind the attitude are real and sometimes inescapable. We must recognize that such administrators are willing to tolerate a certain margin of error and to accept less than the full effectiveness of class numbers. The problem of change is met by them head on and their decisions accept the consequences.
However, our particular concern, as indicated at the beginning of this paper, is the attitude of librarians-administrators of libraries, administrators of so-called technical processes, and practicing catalogers alike-who insist on the values of classification, on the one hand reject outright changes in the system, yet on the other hand indulge in less valid and generally less justifiable change. It is an undeniable fact that many libraries among those which are seriously concerned with classification deviate from official, published versions of the systems they ostensibly follow and defend against change. It would be difficult to find a single library of substantial size using the Dewey Decimal Classification which has not deviated in one or two important ways from the published schedules. Perhaps the commonest deviation is the use by local decision of a number in a particular sense other than that obviously intended by the Dewey Decimal Classification. A library which, for example, omits the use of 327 for foreign relations and instead broadens 34 I.2 to include it, clearly deviates from the published schedules. So does a library which develops an expansion of its own in order to concentrate under one group of numbers materials for which provision clearly exists elsewhere in the schedules. Whether by the use of numbers in a sense not inteneded by the schedules or expansions locally developed which are out of line, logically or structurally, with the published schedules, the libraries which deviate for whatever reason lose the values of library cooperation which result from using a common classification and from centralized classification. There is value to the reader in being able to find in two libraries the same subject matter under the same number. There is a similar temporary value to new members of the staff. The user who was introduced to the classification by his school library is likely to be disconcerted in not 
being able to find in the public library a book for the subject of which he learned the correct class number in school. The library which does not deviate can freely use the class numbers assigned centrally and thus effect a saving in the cost of classification, even aside from the likelihood that numbers are assigned centrally more often by classifiers of special subject competence. One must not leave completely out of consideration the fact that locally developed expansions require continued local editing and expansion and are thus added charge in the cost of classifying the library's collections.

Whether deviations are desirable or not and in spite of the cost, it must be remembered that no library is legally or morally bound to adhere faithfully to the published schedules. That they have deviated so generally is itself evidence that they were free to make the decision. However greatly deviation may be deplored, it is in fact widely practiced. It cannot be reduced or brought to a stop except by a universal recognition and acknowledgement of the value of adhering to the intent of the editors of the published schedules, regardless of differences of opinion in regard to the validity or useableness of the numbers. This is not the expression of a hope or expectation, but merely the statement of the condition under which libraries using the Dewey Decimal Classification can reasonably expect the reduction or elimination by the editors of changes in the schedules.

So long, however, as the purposes and uses of a subject classification are recognized and accepted, the editors must hew to the line and attempt to achieve a classification which is, as far as possible, in accord with present day knowledge. They must of necessity temper validity with expediency and avoid changes which would necessitate large-scale reclassification on the part of libraries that do follow the schedules faithfully and employ a minimum of deviations.
This still leaves other libraries completely free not to change their present practice and to continue to deviate and make their own expansions. The machinery for limiting change is in existence in all libraries that have employed deviations. It lies in the marginal annotations and separate instructions which they have made for their catalogers to follow. Having used this method before, there is nothing these libraries need to do beyond indicating, following every change in the revised schedules, the older number which they would use instead. Inevitably libraries have annotated their copies of the 14th edition; inevitably the Decimal Classification Section annotated its copies of the 14 th and 15 th editions to show the variations which are to be used on the $\mathrm{Li}$ brary of Congress cards. One of the largest public libraries in the country has used the Dewey Decimal Classification selectively regardless of edition; this library inevitably had to go down the line and select from both the $14^{\text {th }}$ and 15 th editions the numbers it chose to use. Where the changes are deemed important enough for a library's purposes, it follows that the necessary expense will be incurred and the change made. In public and school libraries, whose collections do not ordinarily serve the purpose of research, there is a valuable by-product of reclassification: it is the time for weeding-out of the collections out-of-date and otherwise unused books.

In sum: the value of subject classification is generally recognized; it derives its value in part from the validity of its organization and in part from its common use by a number of libraries; in spite of the importance of common use, libraries frequently deviate from the accepted, published form of the classification; the changes which a classification must undergo to retain its validity through the growth of knowledge may be treated by libraries as they treat the existing common classification, that is by accepting the changes on a selective basis. 